\title{
Effect of turmeric powder on performance, carcass traits, humoral immune responses, and serum metabolites in broiler chickens
}

\author{
R. Nouzarian ${ }^{1}$, S.A. Tabeidian ${ }^{1,3}$, M. Toghyani ${ }^{2}$, G. Ghalamkari ${ }^{1}$ \\ and M. Toghyani ${ }^{1}$ \\ ${ }^{I}$ Department of Animal Science, Khorasgan Branch, Islamic Azad University \\ 81595-158 Isfahan, Iran \\ ${ }^{2}$ Young Researchers Club, Khorasgan Branch, Islamic Azad University \\ 81595-158 Isfahan, Iran
}

(Received 18 May 2011; revised version 16 July 2011; accepted 10 August 2011)

\begin{abstract}
The study was conducted to investigate the effect of dietary supplementation with turmeric powder as a natural growth promoter on performance, carcass traits, humoral immune responses and serum biochemical parameters in male broiler chickens. A total of 300 one-day-old male broiler chicks (Ross 308) were allocated to four treatments with five replicates. The dietary treatments consisted of the basal diet as control, 3.3, 6.6 and $10 \mathrm{~g} / \mathrm{kg}$ turmeric powder added to the basal diet. The curcumin content of the turmeric powder was $1.16 \pm 0.03 \%$ by weight. Body weight gain and daily feed intake of chickens at different periods were not influenced by the dietary treatments. Broilers fed turmeric supplemented diets exhibited better feed efficiency over the grower and entire experimental periods in comparison with control group $(\mathrm{P}<0.05)$. A significant decrease $(\mathrm{P}<0.05)$ in abdominal fat pad and liver relative weight was observed in chickens fed the supplemented diets. Inclusion of turmeric powder also caused a marked $(\mathrm{P}<0.05)$ reduction in serum triglyceride concentration but no significant impact of turmeric powder was observed on antibody titer production against Newcastle and influenza viruses. The obtained results suggested that dietary inclusion of turmeric powder failed to induce any significant improvement on performance indexes except feed efficiency of broiler chickens. Nevertheless application of turmeric powder in the diet proved to have positive influence on carcass abdominal fat and serum triglyceride concentration at slaughter age.
\end{abstract}

KEY WORDS: broiler, turmeric powder, performance, carcass traits, serum biochemistry

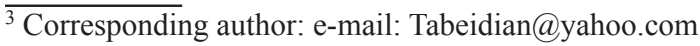




\section{INTRODUCTION}

Antibiotics at subtherapeutic doses have been widely used in animal feed as growth promoters to enhance animal growth performance and production. In the presence of low levels of antibiotics, resistant cells survive and grow producing an antibiotic resistant population in the final products. Therefore, the application of antibiotics as growth promoters in the animal feed has been banned in the European Union since January 2006. As a result of this ban in EU and growing pressure on livestock producers in other parts of the world, alternative substances and strategies for animal growth promotion and disease prevention are being investigated, among which phytogenic and herbal products have received increased attention since they have acquired more acceptability among consumers as natural additives.

Beneficial effects of bioactive plant substances in animal nutrition may include the stimulation of appetite and feed intake, the improvement of endogenous digestive enzyme secretion, activation of immune responses and antibacterial, antiviral and antioxidant actions (Toghyani et al., 2010, 2011). Turmeric (Curcuma longa) is a tropical plant native to southern and southeastern tropical Asia. The main yellow bioactive substances isolated from the rhizomes of Curcuma are curcumin, demethoxycurcumin and bisdemethoxycurcumin which is present to the extent of $2-5 \%$ of the total spice in turmeric powder. Curcumin is the main important bioactive ingredient responsible for the biological activity of curcuma. Curcumin has been shown to have several biological effects, exhibiting anti-inflammatory (Holt et al., 2005), antioxidant (Iqbal et al., 2003) and hypolipidaemic (RamirezTortosa et al., 1999) activities. Curcumin has also been studied extensively as a chemopreventive agent in several cancers (Duvoix et al., 2005). Additionally, it has been suggested that curcumin possess hepatoprotective, antitumor, antiviral and anticancer activity (Polasa et al., 1991). It is used in gastrointestinal and respiratory disorders (Anwarul et al., 2006).

The significant biological properties of turmeric powder make it a potential substitute for infeed antibiotics in livestock diets. A number of studies have been conducted to evaluate its effects on the performance of broiler chickens, laying hens and rabbits, however, the results have not been consistent. Keeping in view the medicinal attributions of Curcuma longa, the current study was designed to evaluate the effects of increasing levels of turmeric powder on performance, carcass characteristics, humoral immune responses and serum biochemical metabolites in male broiler chickens. 


\section{MATERIAL AND METHODS}

\section{Animals and experimental diets}

Fresh Curcuma longa rhizomes purchased from Isfahan local condiments and spices market were cleaned and sliced into small pieces and air dried for two days. The samples were further dried in a hot-air oven at $50^{\circ} \mathrm{C}$ for $24 \mathrm{~h}$ and then ground into powder. The obtained powder was incorporated into the experimental diets. The dietary treatments consisted of the basal diet as control, $3.3,6.6$ and $10 \mathrm{~g} / \mathrm{kg}$ of turmeric powder added to the basal diet instead of maize. Table 1 lists the basal maize-soyabean diets formulated to meet the nutrient

Table 1. Ingredients and composition of the basal diet

\begin{tabular}{lcc}
\hline Item & Starter (0-21 d) & Grower (21-42 d) \\
\hline Diet composition, $g / \mathrm{kg}$ & & \\
maize $(8 \% \mathrm{CP})$ & 536.5 & 628.8 \\
soyabean meal (43\% CP) & 407 & 327.4 \\
soyabean oil & 21.7 & 12.6 \\
calcium carbonate & 12.1 & 12.8 \\
dicalcium phosphate & 14.4 & 10.7 \\
DL-methionine & 1.3 & 0.2 \\
vitamin premix & 2.5 & 2.5 \\
mineral premix ${ }^{2}$ & 2.5 & 2.5 \\
NaCl & 2.5 & 2.5 \\
Calculated chemical composition & & \\
metabolizable energy, kcal/kg & 2900 & 2950 \\
crude protein, g/kg & 208.4 & 189.9 \\
Ca, g/kg & 9 & 8.28 \\
available phosphorous, g/kg & 4.05 & 3.22 \\
methionine + cystine, g/kg & 8.1 & 6.6 \\
lysine, g/kg & 9.9 & 9.2 \\
\hline vitamin premix per kg of diet: mg: vit. A, 2.7 vit. D $0.05 ;$ vit. E, 18; vit. K3 2; thiamine $1.8 ;$ \\
riboflavin 6.6; panthothenic acid 10; pyridoxine 3; cyanocobalamin 0.015; niacin 30; biotin 0.1; \\
folic acid 1; choline chloride 250; antioxidant 100 \\
mineral premix per kg of diet: mg: Fe 50; Mn 100; Zn 100; Cu 10; I 1; Se 0.2
\end{tabular}

requirements of broilers according to NRC (1994); also, the same batch number of ingredients, which contained no antibacterial or anticoccidial supplements, was used to formulate the diets for different periods.

Three hundred, one-day-old male broiler chicks (Ross 308) purchased from a local hatchery, were weighed on arrival and randomly assigned to one of four treatments with five replicates of 15 chicks based on a completely randomized design. Chickens were raised in floor pens $\left(10 \mathrm{birds} / \mathrm{m}^{2}\right)$ litter by sawdust for 
6 weeks. Feed and water were provided ad libitum, throughout the experiment. The lighting programme consisted of $23 \mathrm{~h}$ light and $1 \mathrm{~h}$ of darkness. The house ambient temperature was initially set at $33^{\circ} \mathrm{C}$ by the first week and gradually decreased until $25^{\circ} \mathrm{C}$ was reached by the third week and was then kept constant.

\section{Assay for curcumin content of rhizomes}

Acetonitrile, methanol, acetic acid and deionized water were purchased (all reagents were of analytical grade). Mobile phase reagent containing the following ratio (v:v) mixture of acetonitrile: methanol: water: acetic acid (40:23:36:1) was prepared according to the method of Heath et al. (2003). Five mg of turmeric powder was weighed and dissolved in methanol, making a precise final volume of $5.0 \mathrm{ml}$ with mobile phase reagent to achieve the desired concentration, $1.000 \mu \mathrm{g} / \mathrm{ml}$. Next, the dissolved solution was centrifuged in a bench top centrifuge. An aliquot was removed and further diluted prior to column injection.

Curcumin was separated and quantitated by isocratic high performance liquid chromatography (HPLC), using ultraviolet detection at a wavelength of $262 \mathrm{~nm}$. An aliquot $(50 \mu \mathrm{l})$ was injected onto a reversed-phase column, and the HPLC system consisted of a 410 auto-sampler with refrigeration unit, a 9050 UV visible detector, and a 9010 solvent delivery system with Star 6.30 Chromatography Software (Varian, Walnut Creek, CA). Chromatographic separation was accomplished using a Waters Symmetry Shield $3.9 \times 150 \mathrm{~mm}, 5-\mu \mathrm{m}$ C1 8 column (Waters, Milford, MA). The column was coupled to an Alltech absorbosphere $30 \times 4.6 \mathrm{~mm} \mathrm{C}_{18}$ guard column. The flow rate was $1.0 \mathrm{ml} / \mathrm{min}$. The quantitation of curcumin is by peak area and is based on a standard curve in a methanol matrix, generated by using pure external standard. Turmeric powder samples were analysed in triplicate.

\section{Performance and carcass characteristics}

Chickens were individually weighed at arrival and at 21 and $42 \mathrm{~d}$ of age on a pen basis. Feed consumption was measured per floor pen throughout the experiment and feed conversion ratio (FRC; feed intake/weight gain) was calculated at the same intervals. All the pens were checked for mortality twice a day and the birds that died during the experiment from each group were weighed and sent to the pathology laboratory for necropsy, and feed intake was adjusted accordingly. At $42 \mathrm{~d}$ of age, three birds per replicate randomly chosen were slaughtered and abdominal fat, liver, pancreas, heart, small intestine, bursa and spleen were collected, weighed, and calculated as a percentage of live body weight. The organs were carefully examined to detect any pathological lesion or damages. 


\section{Immune parameters}

Birds were intramuscularly vaccinated against influenza and Newcastle viruses at day 11 of experiment and again against Newcastle via drinking water at 35 day of age. To assess the systemic antibody response to influenza and Newcastle blood samples were collected from brachial vein of vaccinated (three birds per replicate), on $\mathrm{d} 22$ and 42 of the experiment. Blood samples were kept at room temperature for $2 \mathrm{~h}$ and then at $4^{\circ} \mathrm{C}$ overnight. Blood samples were centrifuged at $2000 \mathrm{~g}$ for 10 min to obtain serum (SIGMA 4-15 Lab Centrifuge, Germany); serum was isolated and stored at $-80^{\circ} \mathrm{C}$. Antibody titers against Newcastle and influenza viruses were measured using Hemagglutination Inhibition Test.

\section{Serum biochemical metabolites}

After $12 \mathrm{~h}$ fasting, on day 42 of the experimental period, $3 \mathrm{ml}$ of blood was collected by puncturing the brachial vein from three birds per pen. Serum samples were isolated by centrifugation at $2000 \mathrm{~g}$ for $10 \mathrm{~min}$. Individual serum samples were analysed for total cholesterol, high-density lipoprotein (HDL) and low-density lipoprotein (LDL) cholesterol and triglyceride, by an automatic biochemical analyzer following the instructions of the corresponding reagent kit (Pars Azmoon Co., Teheran, Iran).

\section{Statistical analysis}

Performance data (derived from pen means) were subjected to analysis of variance procedures appropriate for a completely randomized design using the General Linear Model procedure of SAS (2008). Data analysis for the other sampled traits were performed using Mixed Model procedure of SAS followed by considering birds within experimental unit as repeated measures. Tukey-Kramer method was used to assess any significant differences at the probability level of $\mathrm{P}<0.05$ among the experimental treatments.

\section{RESULTS}

\section{Curcumin content, performance and carcass characteristics}

The determined curcumin content of the sample used in our study was relatively low, averaging $1.16 \pm 0.03 \%$ by weight. Experimental treatments had no significant effect on daily feed intake and body weight gain of chicenks at different periods (Table 2). Although final body weight of chicenks fed diet supplemented with 
turmeric powder was numerically higher than in control group, but the differences observed did not reach statistical significance. Supplementation of 3.3, 6.6 and 10 $\mathrm{g} / \mathrm{kg}$ turmeric powder improved feed efficiency over the 21-42 $\mathrm{d}$ and 1-42 $\mathrm{d}$ periods compared with control group $(\mathrm{P}<0.05)$. No significant $(\mathrm{P}>0.05)$ differences due to treatment effects were observed on mortality.

Table 2. Effect of turmeric powder supplementation on performance of broilers at different ages

\begin{tabular}{|c|c|c|c|c|c|c|}
\hline \multirow{2}{*}{$\begin{array}{l}\text { Performance } \\
\text { parameters }\end{array}$} & \multicolumn{4}{|c|}{ Turmeric powder supplement, $\mathrm{g} / \mathrm{kg}$ diet } & \multirow{2}{*}{ SEM } & \multirow[b]{2}{*}{$\mathrm{P}$} \\
\hline & 0 (control) & 3.3 & 6.6 & 10 & & \\
\hline \multicolumn{7}{|c|}{ Body weight, $g$} \\
\hline $21 \mathrm{~d}$ & 717 & 710 & 711 & 702 & 9.2 & 0.94 \\
\hline $42 \mathrm{~d}$ & 2233 & 2277 & 2235 & 2244 & 45.8 & 0.60 \\
\hline \multicolumn{7}{|c|}{ Feed intake, g/d } \\
\hline $1-21 \mathrm{~d}$ & 49.52 & 48.2 & 48.31 & 47.13 & 3.7 & 0.11 \\
\hline $21-42 d$ & 155.9 & 150.3 & 151.9 & 151.7 & 7.4 & 0.06 \\
\hline $1-42 d$ & 107.3 & 99.3 & 101.7 & 99.4 & 4.4 & 0.11 \\
\hline \multicolumn{7}{|c|}{ Feed conversion ratio, $g / g$} \\
\hline $1-21 d$ & 1.6 & 1.58 & 1.58 & 1.56 & 0.02 & 0.80 \\
\hline $21-42 \mathrm{~d}$ & $2.26^{\mathrm{a}}$ & $2.1^{\mathrm{c}}$ & $2.19^{b}$ & $2.16^{\mathrm{bc}}$ & 0.02 & 0.05 \\
\hline $1-42 d$ & $2.01^{\mathrm{a}}$ & $1.83^{\mathrm{b}}$ & $1.9^{\mathrm{ab}}$ & $1.86^{\mathrm{b}}$ & 0.03 & 0.04 \\
\hline
\end{tabular}

a-c Tukey values in rows with no common superscripts differ significantly $(\mathrm{P} \leq 0.05)$

mean values and SEM are based on 5 replications

Data on carcass characteristics and organ weights are presented in Table 3. In the present study carcass yield was not statistically $(\mathrm{P}>0.05)$ influenced by the dietary treatments. However, inclusion of turmeric powder caused a dosedependent decrease in relative weight of abdominal fat pad in comparison with

Table 3. Effect of turmeric powder supplementation on carcass yield, abdominal fat and internal organ weight of broilers at $\mathrm{d} 42$ of age

\begin{tabular}{lcccccc}
\hline \multirow{2}{*}{ arcass traits $^{1}$} & \multicolumn{9}{c}{ Turmeric powder supplement, g/kg diet } & \multirow{2}{*}{ SEM } & \multirow{2}{*}{$\mathrm{P}$} \\
\cline { 2 - 5 } Carcass yield & 0 (control) & 3.3 & 6.6 & 10 & & 0.35 \\
Abdominal fat & 74.3 & 74.6 & 75.3 & 73.5 & 3.33 & 0.04 \\
Liver & $2.05^{\mathrm{a}}$ & $1.41^{\mathrm{b}}$ & $1.37^{\mathrm{b}}$ & $1.52^{\mathrm{b}}$ & 0.22 & 0.01 \\
Heart & $3.17^{\mathrm{a}}$ & $2.67^{\mathrm{b}}$ & $2.66^{\mathrm{b}}$ & $2.43^{\mathrm{b}}$ & 0.33 & 0.01 \\
Pancreas & 0.67 & 0.64 & 0.78 & 0.72 & 0.12 & 0.26 \\
Intestine & 0.27 & 0.21 & 0.26 & 0.24 & 0.13 & 0.08 \\
Bursa of Fabricius & 6.79 & 6.95 & 6.84 & 6.72 & 2.13 & 0.69 \\
Spleen & 0.166 & 0.107 & 0.104 & 0.099 & 0.06 & 0.08 \\
\hline
\end{tabular}

${ }_{1}^{1}$ percentage of live body weight; a-b Tukey values in rows with no common superscripts differ significantly $(\mathrm{P} \leq 0.05)$

mean values and SEM are based on (repeated measure) 3 observations per subject ( 5 subjects per Treatment) 
control chickens $(\mathrm{P}<0.05)$. In addition, birds fed turmeric powder supplemented diets exhibited lower relative weight of liver $(\mathrm{P}<0.05)$ in comparison with control group.

\section{Immune responses}

Table 4 summarizes the effect of dietary treatments on antibody production against influenza and Newcastle viruses at 25 and 42 days of age. Treatments failed to induce any significant $(\mathrm{P}>0.05)$ influence on antibody titres production and no particular trend was observed.

Table 4. Effect of turmeric powder supplementation on antibody titers production against Newcastle disease and influenza at $\mathrm{d} 25$ and 42 of age

\begin{tabular}{|c|c|c|c|c|c|c|}
\hline \multirow{2}{*}{ Variables } & \multicolumn{4}{|c|}{ Turmeric powder supplement, $\mathrm{g} / \mathrm{kg}$ diet } & \multirow{2}{*}{ SEM } & \multirow{2}{*}{$\mathrm{P}$} \\
\hline & 0 (control) & 3.3 & 6.6 & 10 & & \\
\hline \multicolumn{7}{|l|}{ At 25 days } \\
\hline $\begin{array}{l}\text { Newcastle }\left(\log _{2}\right) \\
\text { influenza }\left(\log _{2}\right)\end{array}$ & $\begin{array}{l}2.88 \\
3.7\end{array}$ & $\begin{array}{l}3.5 \\
3.9\end{array}$ & $\begin{array}{l}2.9 \\
3.2\end{array}$ & $\begin{array}{l}2.8 \\
3.4\end{array}$ & $\begin{array}{l}1.6 \\
2.1\end{array}$ & $\begin{array}{l}0.16 \\
0.18\end{array}$ \\
\hline \multicolumn{7}{|l|}{ At 42 days } \\
\hline $\begin{array}{l}\text { Newcastle }\left(\log _{2}\right) \\
\text { influenza }\left(\log _{2}\right)\end{array}$ & $\begin{array}{l}7.2 \\
4.6 \\
\end{array}$ & $\begin{array}{l}6.4 \\
4.7 \\
\end{array}$ & $\begin{array}{l}5.7 \\
4.6 \\
\end{array}$ & $\begin{array}{l}6.3 \\
4.4 \\
\end{array}$ & $\begin{array}{l}1.8 \\
1.5 \\
\end{array}$ & $\begin{array}{l}0.08 \\
0.53 \\
\end{array}$ \\
\hline
\end{tabular}

mean values and SEM are based on (repeated measure) 3 observations per subject ( 5 subjects per Treatment)

\section{Serum biochemical metabolites}

There was no statistical impact of diet supplementation on the concentration of serum low density lipoprotein (LDL), high density lipoprotein (HDL) and total cholesterol (Table 5). Triglyceride concentration of the serum was markedly reduced by turmeric powder inclusion in the diet in comparison with the control $\operatorname{diet}(\mathrm{P}<0.05)$.

Table 5. Effect of turmeric powder supplementation on blood biochemical ${ }^{1}$ parameters of broilers at $\mathrm{d} 42$ of age

\begin{tabular}{lcccccc}
\hline \multirow{2}{*}{ Serum parameters, mg/dl } & \multicolumn{2}{c}{ Turmeric powder supplement, g/kg diet } & \multirow{2}{*}{ SEM } & \multirow{2}{*}{$\mathrm{P}$} \\
\cline { 2 - 5 } & 0 (control) & 3.3 & 6.6 & 10 & & 0.04 \\
\hline Triglyceride & $121^{\mathrm{a}}$ & $96^{\mathrm{bc}}$ & $101^{\mathrm{b}}$ & $80^{\mathrm{c}}$ & 8 & 0.07 \\
Total cholesterol & 114 & 104 & 100 & 98 & 7 & 0.07 \\
LDL $^{1}$-cholesterol & 17 & 23 & 15 & 17 & 5 & 0.69 \\
HDL $^{2}$-cholesterol & 87 & 92 & 86 & 87 & 8 & 0.36 \\
\hline
\end{tabular}

a-c Tukey values in rows with no common superscripts differ significantly $(\mathrm{P} \leq 0.05)$

mean values and SEM are based on (repeated measure) 3 observations per subject ( 5 subjects per Treatment)

${ }^{1} \mathrm{HDL}$ - high-density lipoproteins; ${ }^{2} \mathrm{LDL}$ - low-density lipoproteins 


\section{DISCUSSION}

Performance and carcass characteristics. According to previous reports, it appears that increasing turmeric inclusion rate in broilers diet reduces feed intake but in the present study, it did not differ significantly between the groups. Similar observations were made by Emadi and Kermanshahi (2006) and Durrani et al. (2006) in chickens; the authors reported that at $5 \mathrm{~g} / \mathrm{kg}$ level turmeric significantly decreased feed consumption of chickens, whereas feed intake of birds supplemented with 2,5 and $10 \mathrm{~g} / \mathrm{kg}$ levels turmeric was similar to that of control group. The results obtained on body weight are also in concurrence with Emadi and Kermanshashi (2006) who reported that at an inclusion rate of 2.5, 5 and $7.5 \mathrm{~g} / \mathrm{kg}$ of diet, turmeric had no effect on weight gain of broiler chickens. However, Durrani et al. (2006) found that though at 2.5 and 10 levels, turmeric had no effect on body weight but at an inclusion of $5 \mathrm{~g} / \mathrm{kg}$ body weight was significantly higher. It was concluded that the significant increase in body weight might be due to optimum antioxidant activity of turmeric at the level of $5 \mathrm{~g} / \mathrm{kg}$ that stimulate protein synthesis by enzymatic system.

The most efficient FCR in broilers fed diets supplemented with turmeric powder reveals that the impact of growth promoter substances, such as phytogenic products, on performance could be related to a more efficient use of nutrients, which in turn results in an improved FCR. Turmeric has been reported to exhibit antimicrobial properties and the ethanol turmeric extract demonstrated high potential to inhibit some pathogenic bacteria of shrimp and chicken (Ong-ard et al., 2010). Thus, alike antibiotics, turmeric could control and limit the growth and colonization of numerous pathogenic and non-pathogenic species of bacteria in chickens' gut resulting in balanced gut microbial ecosystems that leads to better feed utilization reflected by improved feed conversion ratio. Corresponding to our results on feed efficiency, Durrani et al. (2006) also reported that chickens receiving diets supplemented with $5 \mathrm{~g} / \mathrm{kg}$ turmeric powder had better feed conversion ratio than 2.5 and $10 \mathrm{~g} / \mathrm{kg}$ supplementation level. Also, Ahmadi (2010) showed that inclusion of turmeric $(0.3$ and $0.6 \mathrm{~g} / \mathrm{kg})$ to the aflatoxin contaminated diets had no effect on feed intake, but significantly increased weight gain and improved feed conversion when compared with birds fed contaminated diets alone.

However, it should be noted that different turmeric species are known to have different levels of curcuminoids (2-7\%). In our study, the determined curcumin content of the sample was relatively low, averaging $1.16 \pm 0.03 \%$ by weight. Curcumin content of turmeric can be influenced by species and different stages of growth at which the plant is harvested. Asghari et al. (2009) reported that the curcumin content of turmeric harvested at different stage of growth ranges from 0.25 to $2.7 \%$, in addition, Reema et al. (2006) showed that the curcumin contents of the selected brands of turmeric from different regions and countries could vary 
from 0.58 to $3.14 \%$ of dry weight. Furthermore, studies have shown that soil factors, including nutrients and level of acidity as well as the genus diversity, may affect the content of curcumin in plants that are the source of turmeric (Sasikumar, 2005). Therefore, the curcumin content of turmeric powder used in different studies could account for the inconsistencies of reports regarding the herb effectiveness on performance indices of broiler chickens.

Similar to our findings on carcass yield, Mehala and Moorthy (2008) failed to observe any significant impact of turmeric powder (up to $10 \mathrm{~g} / \mathrm{kg}$ of diet) on carcass percentage of broiler chickens reared to six weeks of age. On the contrary, Durrani et al. (2006) reported higher dressing percentage, breast, thigh and giblet weight in broilers fed diet containing $5 \mathrm{~g} / \mathrm{kg}$ turmeric powder. Fat deposition in the abdominal area of broilers is regarded as waste in the poultry industry; since it represents a loss in the market and consumer acceptability, and enhances expense during the treatment of effluent produced when processing broilers. The obtained results of this study indicate that turmeric powder supplementation of broilers diet has the potential to lessen this type of waste by reduction of the fat content in the abdominal area of birds. In accord to our results, Samarasinghe et al. (2003) stated that broilers diet supplementation with turmeric (1 and $3 \mathrm{~g} / \mathrm{kg}$ of feed) markedly reduced carcass fat content compared with the control group. Our observations on carcass fat content also are favourably compared with earlier reports of Emadi and Kermanshahi (2006) who observed that the dietary inclusion of turmeric rhizome powder ( 7.5 and $5 \mathrm{~g} / \mathrm{kg}$ of diet) in broiler diets significantly decreased the abdominal fat pad weight. However, Mehala and Moorthy (2008) found no significant difference in abdominal fat pad between treatment groups by inclusion of Aloe vera and Curcuma longa and its combinations. It is likely that curcumin may decrease the activity of the enzymes acting as rate limiting enzymes in lipogenesis such as acetyl-CoA carboxylase, which is the rate-limiting enzyme in fatty acids synthesis.

Interestingly, in line with our observations on liver weight, Ahmadi (2010) indicated the favourable effects of turmeric powder inclusion at 0.3 and $0.6 \mathrm{~g} / \mathrm{kg}$ on liver relative weight of aflatoxin treated chickens. The author reported that addition of all levels of turmeric powder significantly ameliorated the increase in relative weight of liver observed in birds fed aflatoxin alone. In the study of Emadi and Kermanshahi (2007a), the level of $5 \mathrm{~g} / \mathrm{kg}$ turmeric powder showed the highest activity of lactate dehydrogenase (LDH) at 21 days of age and significantly decreased serum alkaline phosphatase (ALP) of the chickens, implying that turmeric might have some positive effects on liver enzymes that directly or indirectly reflect a healthier liver status in broiler chickens.

Immune responses. Curcumin has been reported to possess several pharmacological properties including anti-inflammatory, antimicrobial, antiviral, antifungal, antioxidant, and wound healing activities (Garcea et al., 2005). 
Furthermore, turmeric powder has demonstrated to be a potent immunomodulatory agent that can modulate the activation of T cells, B cells, macrophages, neutrophils, natural killer cells and dendritic cells (Ganesh and Bharat, 2007). Therefore, elevated antibody titer production and consequently better immune responses were expected, but treatments failed to induce any significant influence on antibody titers production and no particular trend was observed. However, Emadi and Kermanshahi (2007b) found that serum immunologlobulins of chickens were also affected by inclusion of turmeric powder into the diets, correspondingly, IgA and IgM at 21 days of age and IgG at 21 and 42 days of age significantly increased in birds fed different turmeric levels.

The lack of statistically significant effects of turmeric on immune responses might be related to the inclusion levels of the additives in the diets. Turmeric powder supplementation levels in the present experiment may not be optimal for enhancing immune responses in chickens. For instance, studies by South et al. (1997) on rats showed that curcumin at a dose of 10 and $20 \mathrm{mg} / \mathrm{kg}$ body weight could not enhance the IgG levels in the NK cells, whereas a higher dose $(40 \mathrm{mg} / \mathrm{kg})$ did elevate IgG levels significantly. More importantly, none of the three doses of curcumin significantly enhanced either delayed-type hypersensitivity or NK cell activity. Also, as previously discussed, the curcumin content can vary from one batch of turmeric powder to another, the percentage has been estimated to be between 1.06 and $5.70 \%$ in 4 different 'commercially available' turmeric samples (Jayaprakasha et al., 2002). Nevertheless, the health status of birds, hygienic status of experimental site, external challenges and basal diets composition and digestibility may to a great extent account for the contradictory and inconsistent reports in the literature regarding the immunomodulatory impact of turmeric powder.

Serum biochemical metabolites The reduction of serum triglyceride by increasing turmeric powder inclusion rate observed in the present study might be due to the reduction of synthetic enzymes activities. Previous studies have indicated that curcumin and an ether extract of turmeric have hypolipaemic action in rats (Rao et al., 1970) and lower cholesterol, fatty acids and triglycerides in alcohol induced toxicity (Rukkumani et al., 2003). Also, Ahmad-Raus et al. (2001) reported that Curcuma domestica had a lowering effect on triglyceride level in the serum of high cholesterol diet animals but showed no effect on serum cholesterol and phospholipid levels. Our findings contrast with the results reported by Emadi et al. (2007) who showed that turmeric supplementation into the basal diets of broiler chickens significantly increased total cholesterol and HDL-cholesterol and decreased LDL-cholesterol, but did not affect total triglyceride, total protein and haematocrit value at 42 days of age.

No clear mechanisms have been reported responsible for the reduction of lipid synthesis by turmeric powder and its bioactive components. However, it has been 
proposed that the activity of liver fatty acid synthase could be influenced by the medicinal plants, leading to modified metabolism of lipids and lipoproteins. Asai and Miyazawa (2001) examined the effect of curcumin on lipid metabolism in rats fed a moderately high-fat diet. Results indicated that liver triacylglycerol and cholesterol concentrations were significantly lower in rats fed curcumin than in control animals. Plasma triacylglycerol in the very low-density lipoproteins fraction were also lower in curcumin fed rats. Hepatic acyl-CoA oxidase activity of the curcumin group was significantly higher than that of the control.

\section{CONCLUSIONS}

Considering the results obtained in the current study it could be concluded that dietary inclusion of turmeric powder may not increase feed consumption and body weight gain in broiler chickens, but has the potential to improve feed efficiency. In addition, turmeric powder had a favourable impact on carcass fat deposition and serum triglyceride concentration at slaughter age, but failed to enhance antibody titer production.

\section{REFERENCES}

Ahmadi F., 2010. Effect of turmeric (Curcuma longa) powder on perfomance, oxidative stress state and some of blood parameters in broiler fed on diets containing aflatoxin $\mathrm{B}_{1}$. Glob. Vet. 5, 312317

Ahmed-Raus R.R., Abdul-Latif E.A., Mohammed J.I., 2001. Lowering of lipid composition in aorta of guinea pigs by Curcuma domestica. BMC Compl. Altern. Med. 1, 6

Anwarul H.G., Abdul J., Muhammad N., Kashif M., 2006. Pharmacological basis for the use of turmeric in gastrointestinal and respiratory disorders. Life Sci. 76, 3089-3105

Asai A., Miyazawa T., 2001. Dietary curcuminoids prevent high-fat diet-induced lipid accumulation in rat liver and epididymal adipose tissue. J. Nutr. 131, 2932-2935

Asghari G., Mostajeran A., Shebli M., 2009. Curcuminoid and essential oil components of turmeric at different stages of growth cultivated in Iran. Res. Pharm. Sci. 4, 55-61

Durrani F.R., Mohammed I., Asal S., Shhail S.M., Naila C., Durrani Z., 2006.Effect of different levels of feed added turmeric (Curcuma longa) on the performance of broiler chicks. J. Agr. Biol. Sci. 1, 9-11

Duvoix A., Blasius R., Delhalle S., Schnekenburger M., Morceau F., 2005. Chemopreventive and therapeutic effects of curcumin. Cancer Lett. 223,181-190

Emadi M., Kermanshahi H., 2006. Effect of turmeric rhizome powder on performance and carcass characteristics of broiler chickens. Int. J. Poultry Sci. 5, 1069-1072

Emadi M., Kermanshahi H., 2007a. Effect of turmeric rhizome powder on the activity of some blood enzymes in broiler chickens. Int. J. Poultry Sci. 6, 48-51

Emadi M., Kermanshahi H., 2007b. Effect of turmeric rhizome powder on immunity responses of broiler chickens. J. Anim. Vet. Adv. 6, 833-836 
Emadi M., Kermanshahi H., Maroufyan E., 2007. Effect of varying levels of turmeric rhizome powder on some blood parameters of broiler chickens fed corn-soybean meal based diets. Int. J. Poultry Sci. 6, 345-348

Ganesh C.J., Bharat B.A., 2007. "Spicing Up" of the immune system by curcumin. J. Clin. Immunol. $27,19-35$

Garcea G., Berry D.P., Jones D.J., Singh R., Dennison A.R., 2005. Consumption of the putative chemopreventive agent curcumin by cancer patients: assessment of curcumin levels in the colorectum and their pharmacodynamic consequences. Cancer Epidem. Biomarker. Prev. 14, 120-125

Heath D.D., Pruitt M.P., Brenner D.E., Rock C.L., 2003. Curcumin in plasma and urine: quantitation by high-performance liquid chromatography. J. Chromatogr. B 783, 287-295

Holt P.R., Katz S., Kirshoff R., 2005. Curcumin therapy in inflammatory bowel disease: a pilot study. Digest. Dis. Sci. 50, 2191-2193

Iqbal M., Sharma S.D., Okazaki Y., Fujisawa M., Okada S., 2003. Dietary supplementation of curcumin enhances antioxidant and phase II metabolizing enzymes in ddY male mice: possible role in protection against chemical carcinogenesis and toxicity. Pharmacol. Toxicol. 92, 33-38

Jayaprakasha G.K., Rao L.J.M., Sakariah K.K., 2002. Improved HPLC method for the determination of curcumin, demethoxycurcumin, and bisdemethoxycurcumin. J. Agr. Food Chem. 50, 36723668

Mehala C., Moorthy M., 2008. Effect of Aloe vera and Curcuma longa (turmeric) on carcass characteristics and biochemical parameters of broilers. Int. J. Poultry Sci. 7, 857-861

NRC, 1994. Nutrient Requirements of Poultry. $9^{\text {th }}$ Edition. National Academy Press. Washington, DC

Ong-ard L., Ngampong K., Boonsong K., 2010. Antimicrobial activity of curcuminoids from Curcuma longa L. on pathogenic bacteria of shrimp and chicken. Kasetsart J. Nat. Sci. 44, 364- 371

Polasa K., Raghuram T.C., Krishna T.P., 1991. Turmeric (Curcuma longa L.) induced reduction in urinary mutagens. Food Chem. Toxicol. 29, 699-706

Ramirez-Tortosa M.C., Mesa M.D., Aguilera M.C., Quiles J.L., Baro L., 1999. Oral administration of a turmeric extract inhibits LDL oxidation and has hypocholesterolemic effects in rabbits with experimental atherosclerosis. Atherosclerosis 147, 371-378

Rao S.D., Chandrashekhara N., Satyanarayana M.N., Srinivasan M., 1970. Effect of curcumin on serum and liver cholesterol levels in the rat. J. Nutr. 100, 1307-1315

Reema F.T., Dennis D. H., Wael K.A., Chery L.R., 2006. Curcumin content of turmeric and curry powders. Nutr. Cancer 55, 126-131

Rukkumani R., Sri Balasubashini M., Menon V.P., 2003. Protective effects of curcumin and photoirradiated curcumin on circulatory lipids and lipid peroxidation products in alcohol and polyunsaturated fatty acid-induced toxicity. Phytother. Res. 17,925-929

Samarasinghe K., Wenk C., Silva K.F.S.T., Gunasekara J.M.D.M., 2003. Turmeric (Curcuma longa) root powder and mannanoligosaccharides as alternatives to antibiotics in broiler chicken diet. Asian-Austr. J. Anim. Sci. 16, 1495-1500

SAS, 2008. Sas User's Guide. Version 9.0. SAS Institute Inc. Cary, NC

Sasikumar B., 2005. Genetics resources of Curcuma: diversity, characterization and utilization. Plant Gen. Res. Charac. 3, 230-251

South E.H., Exon J.H., Hendrix K., 1997. Dietary curcumin enhances antibody response in rats. Immunopharmacol. Immunotoxicol. 19, 105-119

Toghyani M., Toghyani M., Gheisari A.A., Ghalamkari G., Eghbalsaeid S., 2011. Evaluation of cinnamon and garlic as antibiotic growth promoter substitutions on performance, immune responses, serum biochemical and haematological parameters in broiler chicks. Livest. Sci. $138,167-173$

Toghyani M., Toghyani M., Gheisari A.A., Ghalamkari G., Mohammadrezaei M., 2010. Growth performance, serum biochemistry and blood hematology of broiler chicks fed different levels of black seed (Nigella sativa) and peppermint (Mentha piperita). Livest. Sci. 129, 173-178 